\title{
LANDSLIDE STUDY USING TERRESTRIAL LASER SCANNER (LiDAR) ANALYSIS
}

\author{
P. C. Pesántez ${ }^{1 *}$ \\ ${ }^{1}$ University of Cuenca, Engineering Faculty, Cuenca, Ecuador - (pamela.pesantez)@ucuenca.edu.ec
}

Commission III/IVa

KEY WORDS: Remote sensing, Landslide, terrestrial laser scanner, LiDAR, CloudCompare

\begin{abstract}
:
In Reina del Cisne (Cuenca-Ecuador) a dynamic sliding process was created due to a cut that was applied at the beginning of the year 2018 to the hillside without technical considerations for the construction of an access road to a house in the sector. From May 2018 to January 2019, period analyzed in this work, the landslide has caused total structural damage (dwellings near the hillside) or partial (houses away from the hillside) and the total collapse of the path that caused the landslide. The field visits from the month of May 2018 and the comparison with CloudCompare of the clouds of points obtained with terrestrial laser scanner (LiDAR) between the months of May 2018 and January 2019 (house) and December 2018 and January 2019 (profiles) have highlighted the high activity of this gliding. It has been analyzed three-dimensionally several profiles along the landslide, in addition to an affected house, where they have experienced phenomena such as: sinking and tilting to slope down with values from $3 \mathrm{~cm}$ to $30 \mathrm{~cm}$ (profiles) in 30 days to $2.28 \mathrm{~m}$ (house) in 230 days.
\end{abstract}

\section{INTRODUCTION}

Landslides are one of the most destructive geological processes affecting humans, causing deaths and property loses, worth tens of trillions of dollars each year (Brabb \& Harrod, 1989). In the city of Cuenca-Ecuador, it is a common problem that several of its inhabitants aim to build their homes in steep slopes, due to the low prices of these lands and the accelerated growth of the urban area. These slopes experience landslides, which causes damage to homes and constructions in general, as is the case of Reina del Cisne sector. It is essential to carry out monitoring of slides which are of vital importance for the mapping of the same, even for the correct urban planning and prevention of the inhabitants at this risk. This monitoring can be carried out by means of classical techniques of topography in situ such as differential GPS or total station (González-Zúñiga, 2010) combined using active sensors such as RADAR (Bardi et al., 2014; Martie et al., 2016; Ventisette et al., 2014), or the laser scanner (Chen et al., 2014; Eeckhaut et al., 2011; Conner \& Olsen, 2014; Hernandez et al., 2012; Travelletti et al., 2014; Wang et al., 2011).

The objective of this work is to monitor and record sliding movements located on a steep hillside in Reina del Cisne sector (SE Cuenca) that is affecting a group of homes, conclusions and future work.

\section{METHODS}

The study area was delimited with PPGIS. Figure 1 shows the study area. This zone is located at UTM coordinates $17 \mathrm{~s}$ area, $726.775 \mathrm{~m} \mathrm{E}$ and $9.679 .327 \mathrm{~m} \mathrm{~N}$ with an elevation of 2.600 $\mathrm{m}$. This area is characterized by slopes of medium to high.

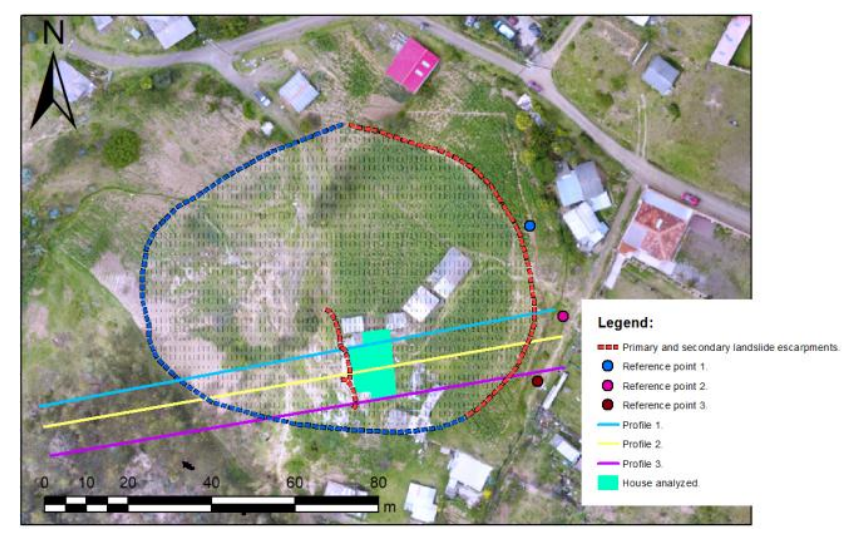

Figure 1. Study area (Cuenca - Ecuador) with information about the landslide and distribution of the profiles studied

\subsection{LiDAR}

The terrestrial LiDAR used has a range of $130 \mathrm{~m}$, an accuracy of $\pm 2 \mathrm{~mm}$, fires an infrared laser in waveform and calculates the distance of the objects depending on the phase of the wave during its departure and return to the sensor. For this type of lifts at short distances, this type of laser scanner based on the wave phase is more productive than the laser pulse-based scanners, which calculate the distance to the objects according to the flight time of the laser. This implies that they are slower, but reach greater distances. For this reason, the use of terrestrial laser scanner is an appropriate method for the study of landslides (Revuelto et al., 2013).

\footnotetext{
* Corresponding author
} 
2.1.1 LiDAR processing: The 7 external individual house scans (May 2018) and two sets of 10 individual scans throughout the study area (December 2018 and January 2019), have joined each other through the FARO Scene(C) software using references.

For the house scans, $140 \mathrm{~mm}$ spheres and checkerboard-type tables and plans of the house were used.

For the two scans throughout the study area, $246 \mathrm{~mm}$ spheres were used. The distance between scans of the house has been less than $15 \mathrm{~m}$, so all the references used to join the scans have received the sufficient number of impacts of the laser to be used for that purpose. On the other hand, the distances of the two sets of scans along the area of study had a distance equal to or greater than $15 \mathrm{~m}$, so they used larger spheres to be able to achieve that these spheres receive sufficient number of impacts to be able to correspond it individually without problem.

To join 2 continuous scans, at least 3 correctly matched references are required (Barbarella \& Fiani, 2013).

While joining scans, it is important to check that the selected references are matched, which can be viewed in the workspace as shown in Figure 2.

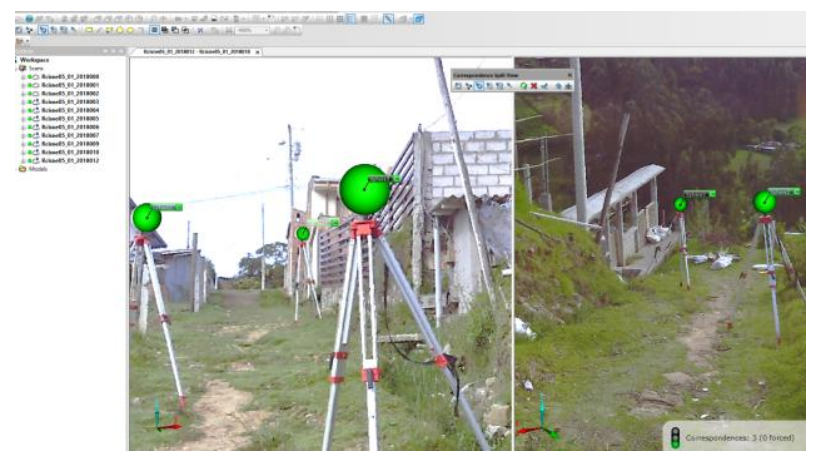

Figure 2. Two continuous scans of LiDAR joined in FARO Scene $\odot$ software

2.1.2 Errors obtained in the scans join: The join of scans to form each of the 3 point clouds was satisfactory. Table 1 shows the highest average error of the 3 dates was only $1.5 \mathrm{~mm}$.

\begin{tabular}{|l|c|c|c|}
\hline Date & \multicolumn{3}{|c|}{ Statistics } \\
\hline & Mean (mm) & Min (mm) & Max (mm) \\
May 2018 & 1.5 & 0 & 1.9 \\
December 2018 & 0.5 & 0 & 1.7 \\
January 2019 & 0.2 & 0 & 1.1 \\
\hline
\end{tabular}

Table 1. Average errors in the scans join

\subsection{CloudCompare}

To align and compare in CloudCompare the point clouds of both dates (December 2018 and January 2019) were used 3 static reference points, located outside the landslide area indicated in Figure 1; in addition, a comparison has been made of the deformations that the dwelling has suffered using the same 3 reference points located outside the main escarpment (May 2018 and January 2019).
2.2.1 Error obtained in the point clouds alignment: The 3 reference points were precisely located and selected in each of the point clouds to align them. The points (A0, A1, and A2) correspond to the December point cloud and the points (R1, R2, and R3) correspond to the January point cloud, for the first alignment, which is indicated in Figure 3. The same process was used in the alignment for May 2018 and January 2019 clouds.

The errors achieved in both alignments were low, because all errors have a value less than $1 \mathrm{~mm}$, as shown in Table 2 and Table 3 .

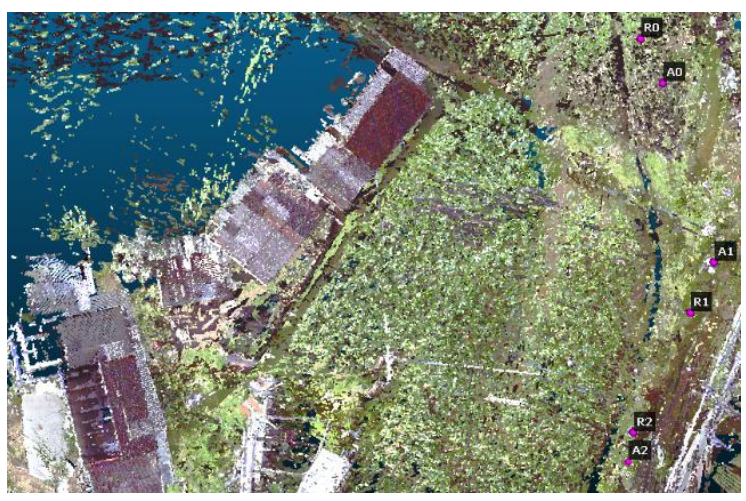

Figure 3. Location of point cloud alignment points

\begin{tabular}{|l|c|}
\hline Points & Error $(\mathrm{mm})$ \\
\hline A0 - R0 & 0.13 \\
A1 - R2 & 0.16 \\
A2 - R2 & 0.12 \\
\hline
\end{tabular}

Table 2. Error values in the alignment between December 2018 and January 2019 clouds

\begin{tabular}{|l|c|}
\hline Points & Error $(\mathrm{mm})$ \\
\hline A0 - R0 & 0.17 \\
A1 - R2 & 0.12 \\
A2 - R2 & 0.10 \\
\hline
\end{tabular}

Table 3. Error values in the alignment between May 2018 and January 2019 clouds

2.2.2 Extraction of analysis areas: After the alignment of the point clouds (May 2018 and January 2019), the area corresponding to the house analyzed was delimited using CloudCompare segment tool as shown in Figure 4. 


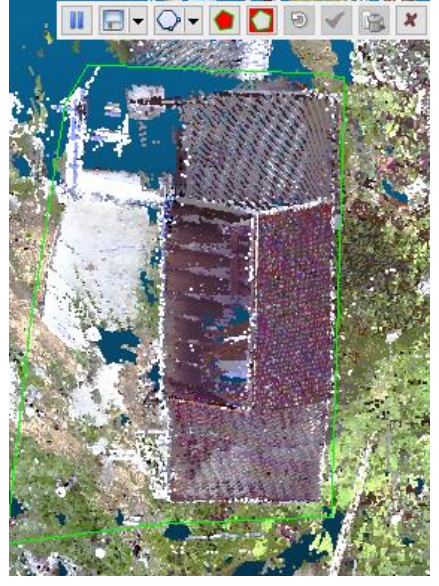

Figure 4. Segment extraction process

2.2.3 Profiling in aligned point clouds: At the end of the alignment of the point clouds (December 2018 and January 2019), 3 profiles are extracted for each point cloud (6 in total) to perform the deformation analysis of the house located in the landslide shown in Figure 1.

Obtaining the profiles is done with the CloudCompare extract cloud section tool as shown in Figure 5, the new point clouds corresponding to the extracted profiles are saved in the las format for use in AutoCAD® Civil 3D.

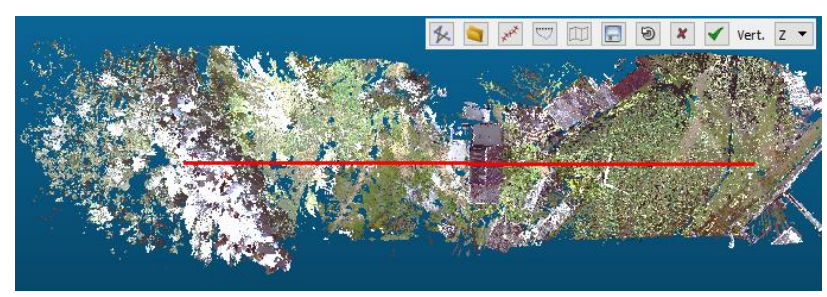

Figure 5. Profile extraction process

\subsection{AutoCAD® Civil 3D}

The profiles obtained in CloudCompare are exported to represent, locate and quantify the movements that the landslide has suffered as shown in Figures 6, 7 and 8.

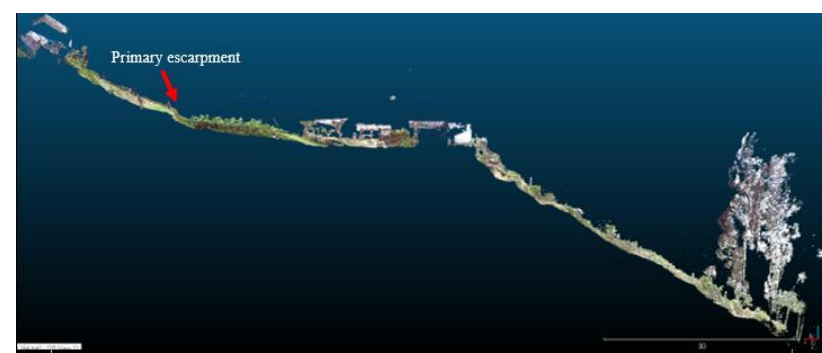

Figure 6. Profile 1 exported to AutoCAD® Civil 3D

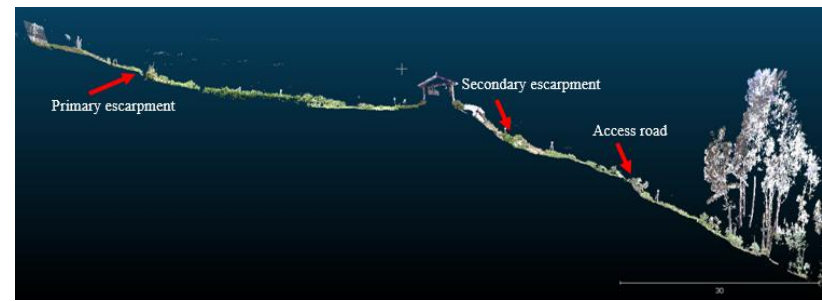

Figure 7. Profile 2 exported to AutoCAD® Civil 3D

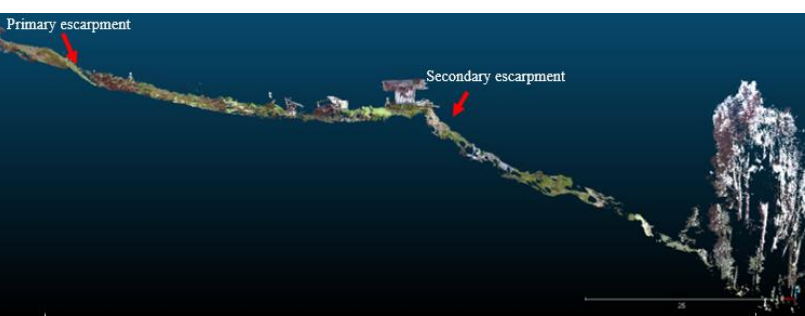

Figure 8. Profile 3 exported to AutoCAD® Civil 3D

\section{DETECTION OF LANDSLIDE ACTIVITY USING EXTRACTED POINT CLOUDS}

For a specific structure, it is measured how much this structure has moved over the time of the study. This process was done using CloudCompare with the 2 clouds of extracted points corresponding to the house analyzed (May 2018 and January 2019).

The segmentation method for scanning profile was used for comparing profiles, consisting segmenting the point cloud following lines. This technique consists of freely drawing a profile, looking to cross perpendicularly the points. The tracing of this line can be done where it is most convenient; in this case, it was where the LiDAR scanner was fixed for scanning (Gonzalez, Woods, \& Eddins, 2004).

Then, the profile representation was generated using AutoCAD® Civil 3D with the profiles extracted from the 2 point clouds (December 2018 and January 2019). This allows obtaining profiles with the respective relevant landslide movements information.

\subsection{Measurement process in a specific structure}

The method for comparing 2 point clouds (May 2018 and January 2019) in CloudCompare consists of 1) segment the the structure to be analyzed;2) locate and select the point at which the movement will be measured within the 2 point clouds; 3 ) read the difference distance between the 2 selected points. Figure 9 shows the process.

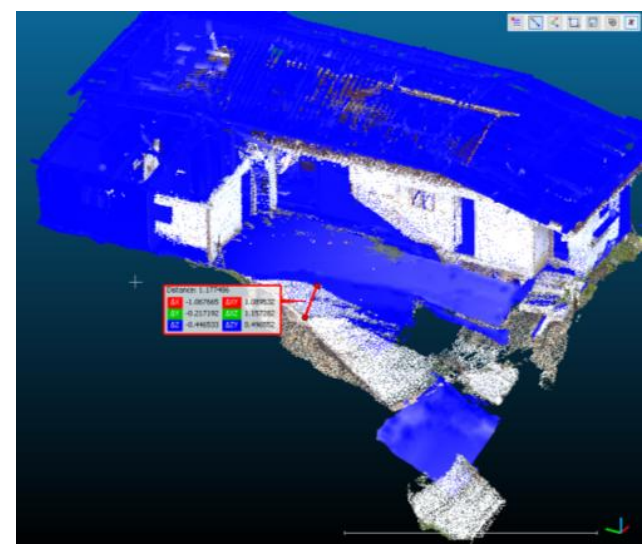

Figure 9. Measurement process in CloudCompare

\subsection{Procedure with extracted profiles}

The method for comparing profiles (December 2018 and January 2019) extracted from CloudCompare consists of 1) export point clouds to AutoCAD ${ }^{\circledR}$ Civil $3 \mathrm{D} ; 2$ ) create a surface from the point cloud; 3) draw a line at the top of the point cloud; 4) create a profile of the surface to which the line corresponds; 5) extract and display the abscissas and heights 
information corresponding to the profile. Figures 10, 11 and 12 show the 3 January 2019 point cloud profiles.

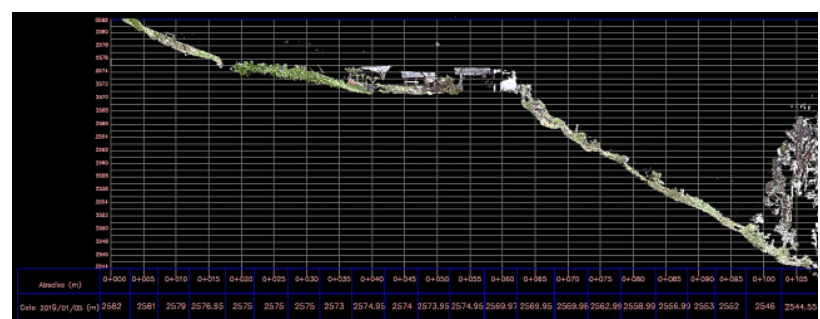

Figure 10. Profile 1 in AutoCAD® Civil 3D

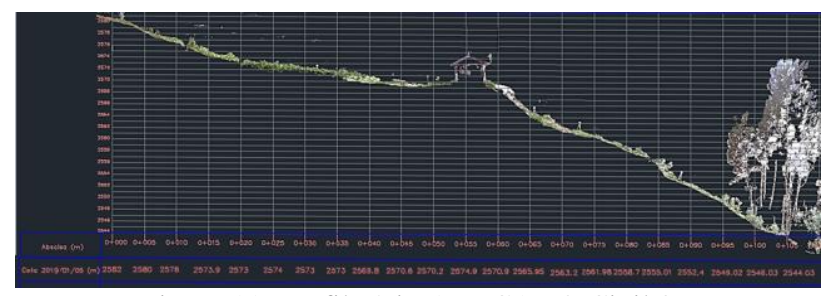

Figure 11. Profile 2 in AutoCAD® Civil 3D

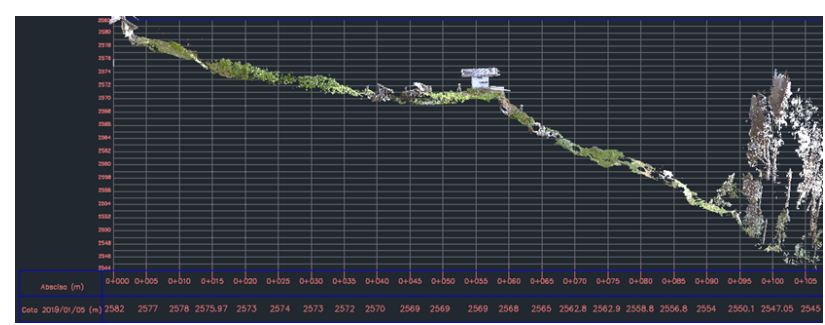

Figure 12. Profile 3 in AutoCAD® Civil 3D

\section{RESULTS}

To measure the movement of the house, different 3 parts of a slab affected by the landslide were selected (May 2018 and January 2019).

For the comparison of profiles, the dimensions of each of the point clouds and their differences were correctly analyzed. For profile comparison, a $5 \mathrm{~m}$ division was used for abscissas and a division of $1 \mathrm{~m}$ for heights. Each profile has been superimposed both clouds points to illustrate and quantify the deformations that has experienced in the area of study in the period of time analyzed (December 2018 and January 2019).

\subsection{Measurement of movement in slab}

Figure 13 shows a sector of the slab of the house scanned, near a secondary landslide escarpment, has shifted $2.28 \mathrm{~m}$ downhill. Figure 14 shows a portion of the slab of the scanned house that has shifted $2.18 \mathrm{~m}$ down the hillside. Figure 15 shows another piece of slab, which has been displaced $2.23 \mathrm{~m}$ downhill and has been slightly tipped. All these structures located in full landslide produced by a secondary escarpment. The result of this alignment has revealed that the landslide has moved significantly in 230 days (May 2018 and January 2019).

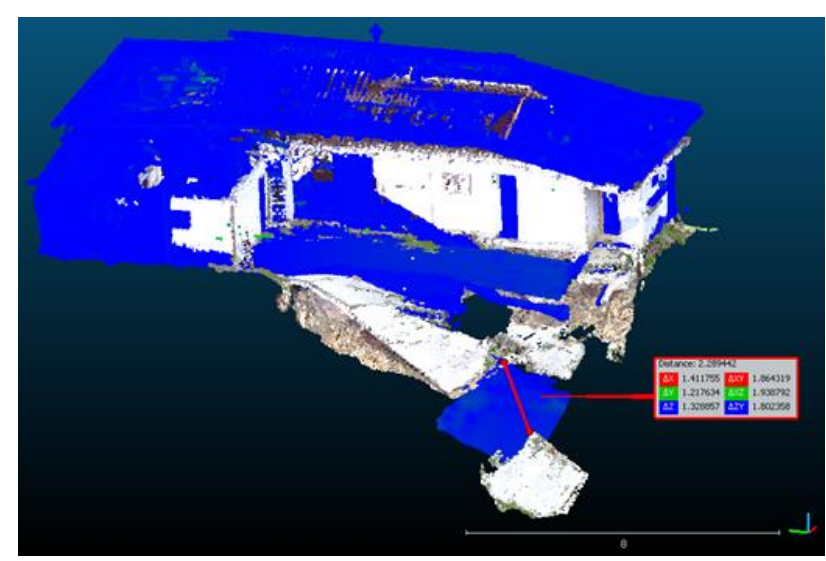

Figure 13. The slab piece has shifted $2.28 \mathrm{~m}$ between May 2018 (blue) and January 2019 (RGB)

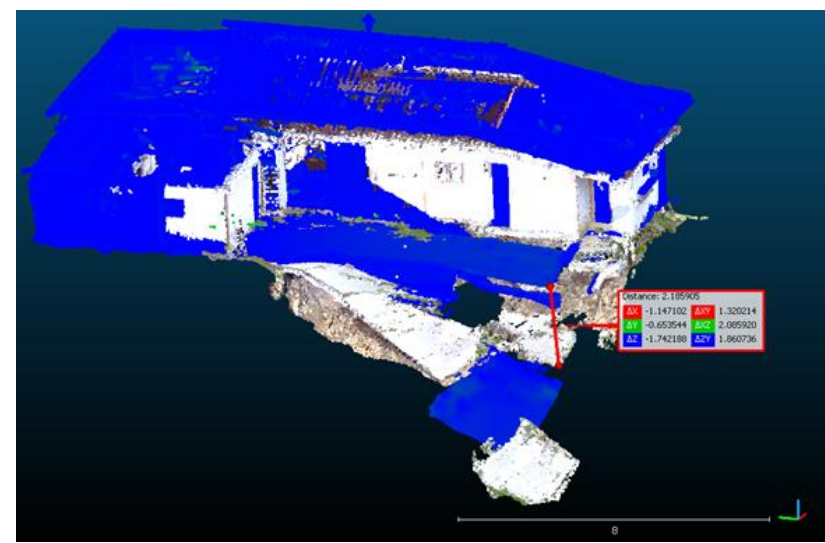

Figure 14. The slab piece has shifted $2.18 \mathrm{~m}$ between May 2018 (blue) and January 2019 (RGB)

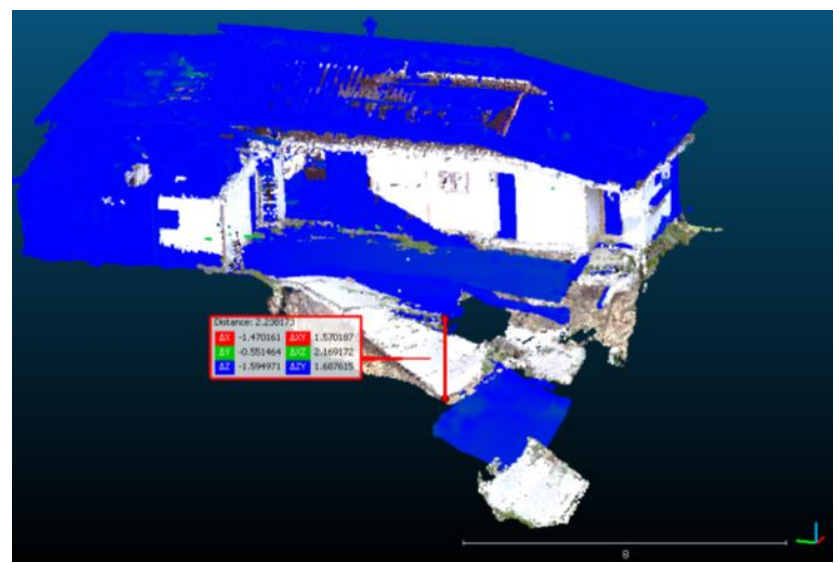

Figure 15. The slab piece has shifted $2.23 \mathrm{~m}$ between May 2018 (blue) and January 2019 (RGB)

\subsection{Profiles comparison}

In Profile 1, 2 and 3, (Figure 1, 16, 17 and 18), it is observed that the main escarpment has increased its height (abscissa $0+$ 015); the growth of corn (abscissa $0+020$ to $0+035$ ) is observed; in general, it is seen as the ground sinks (abscissa $0+$ 040 to $0+090$ ) and as slowly it is rising (abscissa $0+090$ to 0 $+105)$.

In Profile 1, (Figure 16) and Profile 3, (Figure 18) are displayed along the same as the recorded terrain movements, although they are removed from the central axis of the landslide these are produced by mini-slides produced by secondary escarpments. 
In Profile 2, (Figure 17), it can be noticed that the recorded movements are greater, this is because the profile is located in the central axis of the landslide, besides being influenced by the movements of the mini-landslide produced by a secondary escarpment.

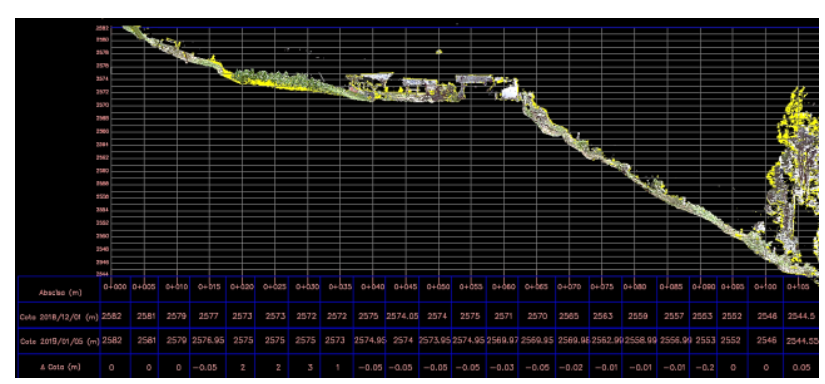

Figure 16. Comparison profile 1

+: Growth or uplift

-: Sinking

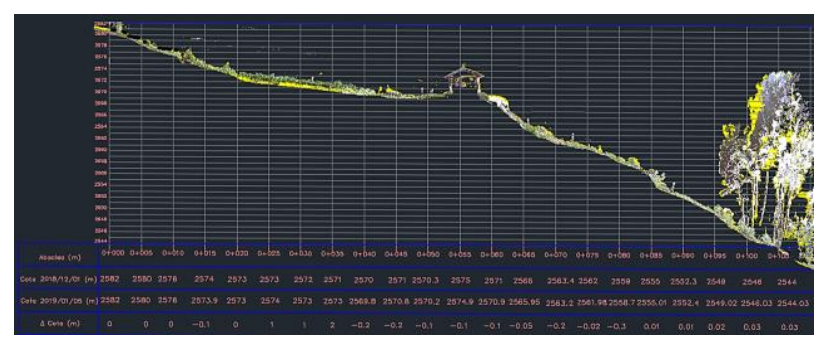

Figure 17. Comparison profile 2

$+:$ Growth or uplift

-: Sinking

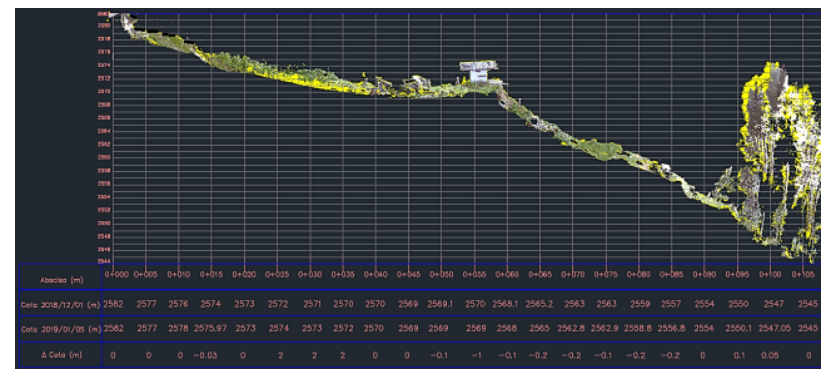

Figure 18. Comparison profile 3

+ : Growth or uplift

-: Sinking

\section{CONCLUSIONS}

According to interviews with the residents, the landslide began in the winter of 2015 as a latent, slow slippage that reactivated only in times of heavy rainfall. Cutting into the hillside, transformed this latent and slow slippage into a very active and fast slide. From May 2018 to January 2019, movements of up to $2 \mathrm{~m}$ have been recorded. Also, in just one month, this new version of the landslide has forced a house to be evacuated because of the important deformations that its structure has experienced.

The results of the profiles confirm that this is a major and rotational landslide, since from abscissa $0+015$ to $0+085$ it is observed that the terrain has been sinking; to the extent that happens from abscissa $0+085$ to $0+105$ where the ground begins slightly to rise. By means of the three profiles analyzed, it is possible to see that the primary escarpment (abscissa $0+015$ ) continues to increase its height, by an average of $6 \mathrm{~cm}$ in this study time: December 2018 and January 2019.
As well, the use of terrestrial laser scanner (LiDAR) for this research has been fundamental, since with this technique has been able to reliably detect the movement generated by a landslide; which could help identify areas vulnerable to this type of problem. But, remote scanning techniques must be complemented by traditional topography techniques to achieve more accurate results.

It is planned to continue monitoring and structural analysis of buildings in this sector with the fundamental support of aerial images of a drone. In this way, it will be possible to monitor the entire landslide and its surroundings.

\section{ACKNOWLEDGEMENTS}

The author wish to thank the Energy Center and the Topography Laboratory of the University of Cuenca for the loan of the terrestrial laser scanner.

\section{REFERENCES}

Barbarella, M., \& Fiani, M., 2013. Monitoring of large landslides by Terrestrial Laser Scanning techniques: field data collection and processing. European Journal of remote sensing, 46(1), 126-151.

Bardi, F., Frodella, W., Ciampalini, A., Bianchini, S., Ventisette, C. Del, Gigli, G., ... Casagli, N., 2014. Integration between ground based and satellite $\{S A R\}$ data in landslide mapping: The San Fratello case study. Geomorphology, 223, 45-60.

Brabb, E. E., \& Harrod, B. L., 1989. Landslides: extent and economic significance. Proceedings of the 28th International Geological Congress: Symposium on Landslides.

Chen, W., Li, X., Wang, Y., Chen, G., \& Liu, S., 2014. Forested landslide detection using LiDAR data and the random forest algorithm: A case study of the Three Gorges, China.

Conner, J. C., \& Olsen, M. J., 2014. Automated quantification of distributed landslide movement using circular tree trunks extracted from terrestrial laser scan data. Computers \& Geosciences, 67, 31-39.

Eeckhaut, M. Van Den, Poesen, J., Gullentops, F., Vandekerckhove, L., \& Hervás, J., 2011. Regional mapping and characterisation of old landslides in hilly regions using LiDAR-based imagery in Southern Flanders. Quaternary Research, 75(3), 721-733.

González-Zúñiga, J. C., 2010. Monitorización de deslizamientos de ladera mediante estación total y GPS diferencial. Aplicación al deslizamiento del kilómetro 35+000 de la vía Loja-Cuenca (Ecuador), 71.

Gonzalez, R. C., Woods, R. E., \& Eddins, S. L. (2004). Digital image processing using MATLAB. (Vol. 624). PearsonPrentice-Hall Upper Saddle River.

Hernández, M. a., Pérez-García, J. L., Fernández, T., Cardenal, F. J., Mata, E., López, A., ... Mozas, A., 2012. Methodology for landslide monitoring in a road cut by means of terrestrial laser-scanning techniques. International Archives of the Photogrammetry, Remote Sensing and Spatial Information Sciences - ISPRS Archives, 39(September), 21-26.

Martire, D. Di, Tessitore, S., Brancato, D., Ciminelli, M. G., Costabile, S., Costantini, M., ... Calcaterra, D., 2016. Landslide detection integrated system (LaDIS) based on insitu and satellite $\{S A R\}$ interferometry measurements. \{CATENA\}, 137, 406-421. 
Revuelto, J., López-Moreno, J. I., Azorín-Molina, C., Arguedas, G., Vicente Serrano, S. M., \& Serreta Oliván, A., 2013. Utilización de técnicas de láser escáner terrestre en la monitorización de procesos geomorfológicos dinámicos: el manto de nieve y heleros en áreas de montaña.

Travelletti, J., Malet, J.-P., \& Delacourt, C., 2014. Image-based correlation of Laser Scanning point cloud time series for landslide monitoring. International Journal of Applied Earth Observation and Geoinformation, 32(0), 1-18.

Ventisette, C., Righini, G., Moretti, S., \& Casagli, N., 2014. Multitemporal landslides inventory map updating using spaceborne $\{S A R\}$ analysis. International Journal of Applied Earth Observation and Geoinformation, 30, 238246.

Wang, G., Philips, D., Joyce, J., \& Rivera, F., 2011. The integration of TLS and continuous GPS to study landslide deformation: a case study in Puerto Rico. Journal of Geodetic Science, 1(1), 25-34. 